\title{
Prognostic Value of Preoperative Fibrinogen for Predicting Clinical Outcome in Patients with Nonmetastatic Colorectal Cancer
}

This article was published in the following Dove Press journal: Cancer Management and Research

\author{
Yu Sun* \\ Weiying Han* \\ Yongxi Song (iD \\ Peng Gao \\ Yuchong Yang \\ Dehao Yu \\ Yu Wang \\ Zhenning Wang
}

Department of Surgical Oncology and General Surgery, Key Laboratory of Precision Diagnosis and Treatment of Gastrointestinal Tumors, Ministry of Education, First Hospital of China Medical University, Shenyang City I I000I, People's Republic of China

*These authors contributed equally to this work
Correspondence: Zhenning Wang Department of Surgical Oncology and General Surgery, Key Laboratory of Precision Diagnosis and Treatment of Gastrointestinal Tumors, Ministry of Education, First Hospital of China Medical University, Shenyang II000I, People's Republic of China

Tel +86-24-83283556

$\mathrm{Fax}+86-24-22703578$

Email josieon826@sina.cn
Background: The prognostic role of preoperative fibrinogen in colorectal cancer (CRC) patients remains controversial. Therefore, we assessed the predictive value of preoperative fibrinogen and developed a tool for predicting the survival of CRC patients.

Methods: This retrospective study evaluated 1869 patients who underwent curative resection for CRC. Univariate and multivariate survival analyses were conducted to identify the factors correlated with overall survival (OS) and cancer-specific survival (CSS). Nomograms were developed as a graphical representation of the Cox proportional hazards regression models. The performance of the nomograms was assessed by Harrell's concordance index (c-index) and calibration plots.

Results: The preoperative fibrinogen levels were correlated with age, tumor differentiation, tumor location, pT category, and TNM stage. In the multivariate analysis, elevated fibrinogen level was independently correlated with worse OS and CSS (OS: hazard ratio [HR] $=0.777$, $95 \%$ confidence interval $[95 \% \mathrm{CI}]=0.630-0.958, \mathrm{P}=0.018$; $\mathrm{CSS}: \mathrm{HR}=0.757,95 \% \mathrm{CI}=$ $0.605-0.947, \mathrm{P}=0.015$ ). The nomograms could predict outcomes with a c-index for OS and CSS of 0.79 and 0.81 , respectively. The nomograms also had a good calibration.

Conclusion: Preoperative fibrinogen level was an independent marker of poor prognosis in patients with nonmetastatic CRC, and there was a threshold level for the use of fibrinogen as a prognostic factor. Furthermore, nomograms may help predict the individual risk of OS and CSS in patients treated for CRC.

Keywords: colorectal cancer, fibrinogen, prognosis, TNM staging, nomogram

\section{Background}

Colorectal cancer (CRC) is the second most commonly diagnosed cancer in women and third in men, with an estimated 1.4 million cases and 693,900 deaths in 2012 worldwide. ${ }^{1}$ Westernized lifestyle significantly increases the prevalence of obesity and physical inactivity in recent decades and may have contributed to the increase in the incidence of $\mathrm{CRC}^{2-7}$ To date, TNM staging has been the most commonly used prognostic indicator. However, the survival difference exists within the same TNM stage. ${ }^{8}$ Host factors such as the systemic inflammation may be responsible for the observed differences in survival. ${ }^{9-13}$ Therefore, the development of simple, noninvasive methods is important for the accurate assessment of patient prognosis.

Fibrinogen is a soluble glycoprotein produced by hepatocytes and converted into fibrin by activated thrombin. ${ }^{14,15}$ It plays a major role in blood clotting, cellular and matrix interactions, and wound healing. ${ }^{16,17}$ In addition, fibrinogen may be 
affected by the presence of inflammation. However, the mechanism involved in the synthesis of activated fibrinogen during inflammation is not fully understood.

Studies have shown that higher levels of fibrinogen are correlated with an increased risk of developing CRC. ${ }^{18,19}$ The prognostic role of preoperative fibrinogen in CRC patients remains controversial. Son et al suggested that elevated fibrinogen levels may serve as a prognostic indicator in patients with nonmetastatic colon cancer. ${ }^{20}$ However, Pedrazzani et al showed that preoperative fibrinogen levels associated with major prognostic factor but did not help predict patient outcome after CRC surgery. ${ }^{21}$ The primary objective of this study was to investigate the prognostic prediction value of preoperative fibrinogen level in nonmetastatic CRC. The secondary objective was to construct predictive models and nomograms to predict the survival of nonmetastatic CRC patients.

\section{Methods}

\section{Patient Cohort}

We retrospectively analyzed a cohort of CRC patients who underwent primary tumor resection at the Department of Surgical Oncology at the First Hospital of China Medical University (CMU-SO). According to National Comprehensive Cancer Network (NCCN) guideline, adjuvant chemotherapy is recommended for high-risk stage II patients and stage III patients enrolled in the study, while it is recommended for low-risk stage II patients according to their physical status. Patients without recorded preoperative fibrinogen levels, those with metastatic disease, and those who received preoperative chemoradiotherapy were excluded. Therefore, 1869 patients were included in the study. Patients were diagnosed and treated from April 2000 to May 2014. Follow-up was completed until October 2015. Median follow-up was 46 months (range of 4-136). Clinical data, including age, sex, clinicopathological features, and preoperative laboratory data, were obtained from the medical records of the patients. Blood parameters were measured in early-morning samples collected 1 to 14 days before surgery. The albumin level was obtained using the hepatic function test, and neutrophil, lymphocyte, and platelet counts were collected using a routine blood test. PNI was calculated as $10 \times$ albumin level $(\mathrm{g} / \mathrm{dl})+0.005 \times$ total lymphocyte count $\left(\right.$ per mm3). ${ }^{22}$ The CRC stage was classified according to the eighth edition of the AJCC/UICC TNM classification system.

\section{Statistical Analysis}

Categorical variables were presented as absolute values. The association between preoperative fibrinogen levels and clinicopathologic data was evaluated using nonparametric tests and Spearman rank-order correlation. Survival curves were depicted using the Kaplan-Meier method and compared using the Log rank test. Significant prognostic factors for OS and CSS were included in the multivariate Cox regression analysis by using a backward step-wise method. The performance in predicting the outcome was evaluated with the c-index, which is equivalent to the area under the receiver operating characteristic curve. The maximum c-index value (1.0) indicates perfect prediction, whereas 0.5 indicates a random chance of correct prediction. Nomograms were formulated on the basis of the results of the multivariate Cox regression analysis. Calibration was assessed by comparing nomogrampredicted versus observed outcomes.

We quantified discrimination and determined the optimal cut-off values for inflammatory biomarkers using the Bayesian information criterion (BIC). ${ }^{23} \mathrm{~A}$ smaller BIC value indicated a better model for predicting the outcome. Restricted cubic spline functions were used to estimate the dose-response association between the continuous variable and the outcome. ${ }^{24,25}$

Statistical analysis was conducted using STATA software version 14.0 (Stata Corporation, College Station, TX, USA), SPSS software version 22.0 (SPSS, Chicago, IL, USA) and R software version 3.3.2 (http://www.Rproject. org). A p-value of less than 0.05 from a two-tailed test was considered statistically significant.

\section{Results}

The correlations between preoperative fibrinogen levels and clinicopathological features are shown in Table 1. The mean preoperative fibrinogen level was $3.81 \pm 0.86$ $\mathrm{g} / \mathrm{L}$. Preoperative fibrinogen levels were significantly correlated with age, tumor differentiation, tumor location, $\mathrm{pT}$ category, and TNM stage $(\mathrm{P}<0.05)$ but were not significantly associated with sex $(\mathrm{P}=0.299)$ and $\mathrm{pN}$ category ( $\mathrm{P}=0.359)$.

The results of the univariate analysis indicated that the preoperative fibrinogen levels were significantly associated with prognosis of OS and CSS (Supplementary Table 1). Tumor differentiation, tumor stage, neutrophil count, lymphocyte count, platelet count, albumin level, neutrophil to lymphocyte ratio (NLR), platelet to 
Table I Associations of Preoperative Fibrinogen Levels with Clinicopathologic Characteristics

\begin{tabular}{|c|c|c|c|}
\hline Variable & $\begin{array}{l}\text { No. of } \\
\text { Patients } \\
\text { (\%) }\end{array}$ & $\begin{array}{l}\text { Mean } \\
\text { Preoperative } \\
\text { Fibrinogen } \\
\text { Level, g/L } \\
\text { (Standard } \\
\text { Deviation) }\end{array}$ & $P$ value \\
\hline $\begin{array}{l}\text { Age, years } \\
\quad \geq 62 \\
<62\end{array}$ & $\begin{array}{l}953(51.0) \\
916(49.0)\end{array}$ & $\begin{array}{l}3.90(0.88) \\
3.7 I(0.84)\end{array}$ & $<0.001$ \\
\hline $\begin{array}{l}\text { Sex } \\
\qquad \text { Male } \\
\text { Female }\end{array}$ & $\begin{array}{l}1059(56.7) \\
810(43.3)\end{array}$ & $\begin{array}{l}3.80(0.88) \\
3.82(0.84)\end{array}$ & 0.299 \\
\hline $\begin{array}{l}\text { Differentiation } \\
\text { Well-moderate } \\
\text { Poor-undifferentiated }\end{array}$ & $\begin{array}{l}17 \mid 3(91.7) \\
156(8.3)\end{array}$ & $\begin{array}{l}3.68(0.82) \\
4.08(1.03)\end{array}$ & 0.001 \\
\hline $\begin{array}{l}\text { Tumor location } \\
\text { Colon } \\
\text { Rectum }\end{array}$ & $\begin{array}{l}788(42.2) \\
108 \mid(57.8)\end{array}$ & $\begin{array}{l}3.96(0.91) \\
3.69(0.82)\end{array}$ & $<0.001$ \\
\hline $\begin{array}{l}\text { PT category } \\
\text { TI } \\
\text { T2 } \\
\text { T3 } \\
\text { T4 }\end{array}$ & $\begin{array}{l}51(2.7) \\
346(18.5) \\
744(39.8) \\
728(39.0)\end{array}$ & $\begin{array}{l}3.34(0.83) \\
3.56(0.81) \\
3.88(0.88) \\
3.88(0.84)\end{array}$ & $<0.001$ \\
\hline $\begin{array}{l}\mathrm{pN} \text { category } \\
\mathrm{N} 0 \\
\mathrm{~N} 1 \\
\mathrm{~N} 2\end{array}$ & $\begin{array}{l}1121(60.0) \\
552(29.5) \\
196(10.5)\end{array}$ & $\begin{array}{l}3.81(0.86) \\
3.77(0.86) \\
3.87(0.86)\end{array}$ & 0.359 \\
\hline $\begin{array}{l}\text { PTNM stage } \\
\text { I } \\
\text { II } \\
\text { III }\end{array}$ & $\begin{array}{l}323(17.3) \\
798(42.7) \\
748(40.0)\end{array}$ & $\begin{array}{l}3.52(0.81) \\
3.93(0.86) \\
3.80(0.86)\end{array}$ & $<0.001$ \\
\hline
\end{tabular}

lymphocyte ratio (PLR), PNI, and tumor deposits were also significantly associated with OS and CSS. Age and the total number of examined lymph nodes showed a significant association with OS. Sex, tumor size, tumor location, PT, and APTT were not significantly correlated with survival in the univariate analysis. In the multivariate analysis, age, pT category, $\mathrm{pN}$ category, neutrophil count, total number of examined lymph nodes, tumor deposits, and PLR were independent prognostic predictors of OS, whereas the fibrinogen levels (continuous variable) were not $(\mathrm{HR}=1.029,95 \% \mathrm{CI}=0.917-1.155$, $\mathrm{P}=0.628$, Supplementary Table 1). Similar result was found for CSS $(\mathrm{HR}=1.052,95 \% \mathrm{CI}=0.930-1.191, \mathrm{P}=$ 0.419 , Supplementary Table 1). The dose-response relationship between fibrinogen levels and prognosis of cancer was estimated by the method of restricted cubic splines. The results indicated that the effect of fibrinogen levels on the prognosis of OS did not increase significantly until a level of 3.6-3.7 g/L; for higher levels, the prognosis was not further deteriorated as the fibrinogen levels continued to increase (Figure 1). Survival analysis was conducted according to the fibrinogen levels (Supplementary Figure 1). The plotting of the survival analysis for eight groups according to the fibrinogen levels $(<2.91, \quad 2.91 \leq$ and $<3.20, \quad 3.20 \leq$ and $<3.43$, $3.43 \leq$ and $<3.64,3.64 \leq$ and $<3.90,3.90 \leq$ and $<4.24$, $4.24 \leq$ and $<4.76, \geq 4.76 \mathrm{~g} / \mathrm{L})$ generated eight curves, which were distributed in two groups (Supplementary Figure $1 \mathrm{~A}$ and $\mathrm{B})$. In the subgroup analysis, there was no difference in survival among the four groups (Supplementary Figure 1C-F).

The BIC method was used to determine the optimal cut-off values of fibrinogen. The consistency of the study variables was maintained by using the same method to define the cut-off values for the inflammatory biomarkers, including NLR, PLR, and PNI (Supplementary Table 2). After modeling fibrinogen as a dichotomous variable (fibrinogen $\geq 3.64 \mathrm{~g} / \mathrm{L}$ and $<3.64 \mathrm{~g} / \mathrm{L}$ ), KaplanMeier survival analysis with Log rank tests and univariate analysis were conducted to evaluate the association between fibrinogen levels and prognosis. The OS was significantly higher in patients with low fibrinogen levels compared with patients with high fibrinogen levels $(\mathrm{P}<$ 0.001 , Figure 2A). Similar survival differences were observed for CSS $(\mathrm{P}<0.001$, Figure $2 \mathrm{~B})$. We also identified the effect of age on the prognosis in patients with different fibrinogen levels. The Kaplan-Meier survival analysis stratified by age ( $<62$ and $\geq 62$ years) revealed significant differences in survival among younger patients (Supplementary Figure 2).

In contrast to the results of the previous analysis using continuous variables, fibrinogen level was identified as an independent prognostic factor in the multivariate analysis $(\mathrm{P}=0.018$ for OS; $\mathrm{P}=0.015$ for CSS, Table 2 and Supplementary Table 3). Age, pT category, pN category, albumin level, total number of examined lymph nodes, and tumor deposits were also independently and significantly associated with OS (Table 2). Tumor deposits, pT category, pN category, neutrophil count, lymphocyte count, and albumin level were significantly associated with CSS (Supplementary Table 3). 


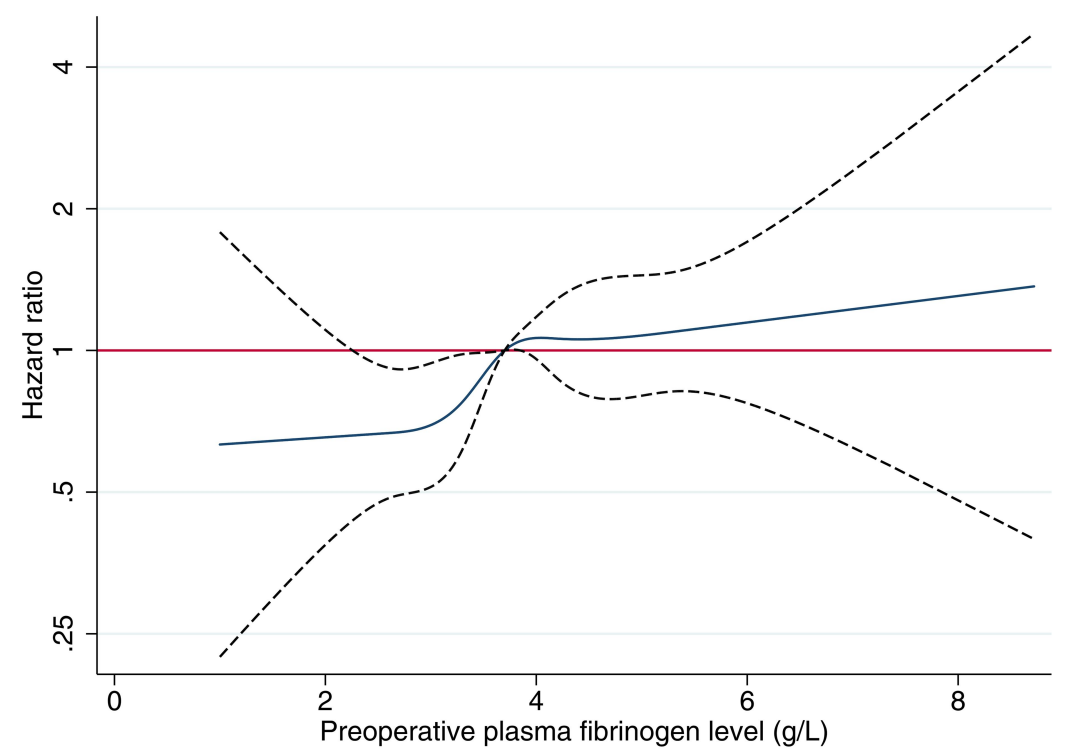

Figure I Estimates of the hazard ratio and $95 \%$ confidence interval of CRC using the restricted cubic spline model by the preoperative fibrinogen level.

\section{OS}

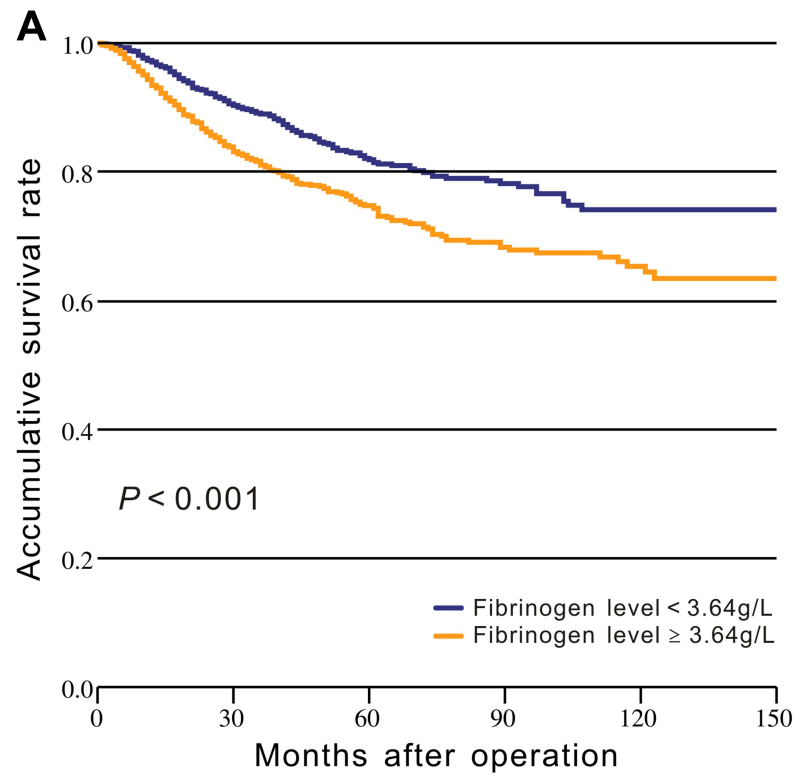

CSS

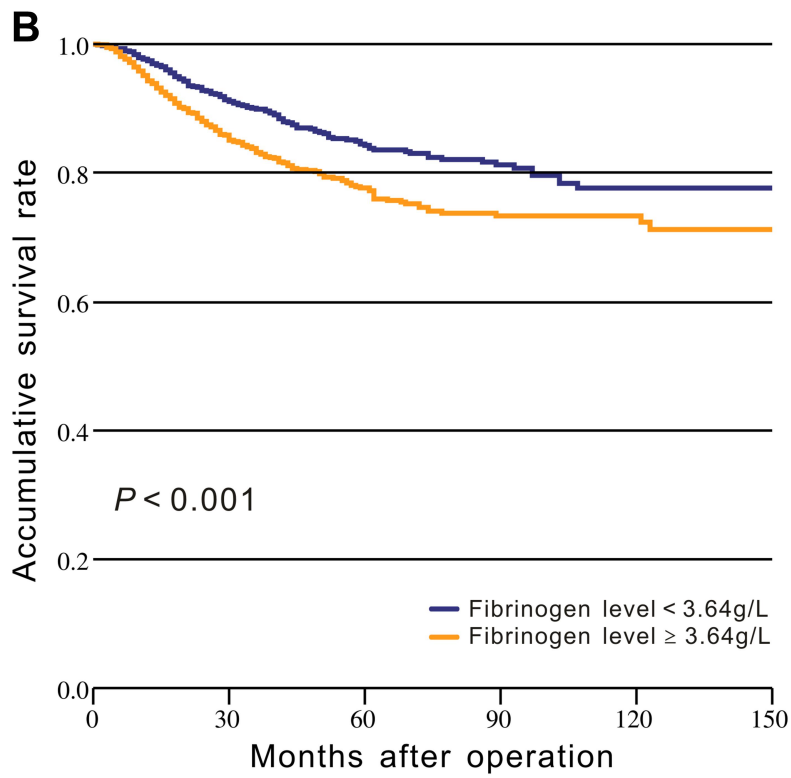

Figure 2 Kaplan-Meier analysis of survival based on low and high fibrinogen levels among the patients from the CMU-SO: (A) Overall survival; (B) Cancer-specific survival.

To provide clinicians with a quantitative tool to predict individual prognosis, we built the nomogram on the basis of the multivariate logistic analysis in the primary cohort. Two prognostic nomograms for OS and CSS are shown in Figure 3. The nomograms could estimate probability by assigning a score ("Points" scale) to each predictor variable. The sum of these variable scores corresponds to an outcome probability (outcome scale). In both nomograms, pathologic staging was the most important factor. The c-index for prediction of OS and CSS was 0.79 (95\% CI: 0.77-0.81) and 0.81 (95\% CI: 0.78-0.83), respectively. The results indicated that the nomograms were superior to $\mathrm{TNM}$ classification (c-index for $\mathrm{OS}=0.72,95 \% \mathrm{CI}=$ $0.70-0.74$; for $\mathrm{CSS}=0.74,95 \% \mathrm{CI}=0.72-0.76$ ). The calibration curve showed an optimal agreement between the prediction and actual observation (Supplementary Figure 3). This illustration demonstrated good calibration of the nomograms. 
Table 2 Univariate and Multivariate Survival Analyses of OS in Patients with Colorectal Cancer

\begin{tabular}{|c|c|c|c|c|}
\hline \multirow[t]{2}{*}{ Variable } & \multicolumn{2}{|l|}{ Univariate } & \multicolumn{2}{|l|}{ Multivariate } \\
\hline & HR (95\% Cl) & $\mathbf{P}$ & HR (95\% CI) & $\mathbf{P}$ \\
\hline Age & 1.018 (1.009-1.028) & $<0.001$ & 1.017 (1.008-1.028) & $<0.001$ \\
\hline $\begin{array}{l}\text { Sex } \\
\qquad \text { Male } \\
\text { Female }\end{array}$ & $\begin{array}{l}\text { I } \\
0.825(0.677-1.006)\end{array}$ & 0.057 & & \\
\hline Tumor Size & I.048 (0.998-I.I00) & 0.060 & & \\
\hline $\begin{array}{l}\text { Tumor location } \\
\text { Colon } \\
\text { Rectum }\end{array}$ & $\begin{array}{l}\text { I } \\
1.057(0.868-1.286)\end{array}$ & 0.584 & & \\
\hline $\begin{array}{l}\text { Differentiation } \\
\text { Well- moderate } \\
\text { Poor-undifferentiated }\end{array}$ & $\begin{array}{l}\text { I } \\
2.221(1.679-2.938)\end{array}$ & $<0.001$ & & \\
\hline $\begin{array}{l}\text { PT category } \\
\text { T1 } \\
\text { T2 } \\
\text { T3 } \\
\text { T4 }\end{array}$ & $\begin{array}{l}\text { I } \\
\text { I.848 }(0.57 \mid-5.988) \\
4.304(1.376-13.469) \\
6.319(2.018-19.788)\end{array}$ & $<0.001$ & $\begin{array}{l}\text { I } \\
\text { I.566 (0.482-5.086) } \\
2.102(0.665-6.642) \\
2.994(0.945-9.485)\end{array}$ & $<0.001$ \\
\hline $\begin{array}{l}\mathrm{pN} \text { category } \\
\mathrm{N} 0 \\
\mathrm{~N} 1 \\
\mathrm{~N} 2\end{array}$ & $\begin{array}{l}\text { I } \\
4.142(3.266-5.252) \\
10.531(8.076-13.732)\end{array}$ & $<0.001$ & $\begin{array}{l}\text { I } \\
3.460(2.695-4.442) \\
9.096(6.856-12.066)\end{array}$ & $<0.001$ \\
\hline $\begin{array}{l}\text { PTNM stage } \\
\text { I } \\
\text { II } \\
\text { III }\end{array}$ & $\begin{array}{l}1 \\
1.979(1.217-3.218) \\
8.962(5.697-14.099)\end{array}$ & 0.001 & & \\
\hline $\begin{array}{l}\text { Neutrophil count } \\
\geq 3.61 \times 10^{9} / \mathrm{L} \\
<3.61 \times 10^{9} / \mathrm{L}\end{array}$ & $\begin{array}{l}\text { I } \\
0.682(0.559-0.832)\end{array}$ & $<0.001$ & $\begin{array}{l}\text { I } \\
0.815(0.642-1.034)\end{array}$ & 0.093 \\
\hline $\begin{array}{l}\text { Lymphocyte count } \\
\qquad 1.35 \times 10^{9} / \mathrm{L} \\
<1.35 \times 10^{9} / \mathrm{L}\end{array}$ & $\begin{array}{l}\mathrm{I} \\
1.521(1.190-1.945)\end{array}$ & 0.001 & $\begin{array}{l}\text { I } \\
\text { I.308 (0.987-I.734) }\end{array}$ & 0.062 \\
\hline $\begin{array}{l}\text { Platelet count } \\
\qquad 280 \times 10^{9} / \mathrm{L} \\
<280 \times 10^{9} / \mathrm{L}\end{array}$ & $\begin{array}{l}\text { I } \\
0.786(0.635-0.972)\end{array}$ & 0.026 & & \\
\hline $\begin{array}{l}\text { Albumin level } \\
\geq 34.6 \mathrm{~g} / \mathrm{L} \\
<34.6 \mathrm{~g} / \mathrm{L} \\
\text { The total number of eLNs } \\
\text { Tumor deposits } \\
\text { PT } \\
\text { APTT }\end{array}$ & $\begin{array}{l}I \\
1.779(1.292-2.448) \\
0.990(0.98 I-1.000) \\
1.200(1.165-1.237) \\
1.042(0.97 I-1.117) \\
1.007(0.992-1.022)\end{array}$ & $\begin{array}{l}0.041 \\
<0.001 \\
0.252 \\
0.367\end{array}$ & $\begin{array}{l}\text { I } \\
1.678(1.203-2.341) \\
0.984(0.975-0.994) \\
1.102(1.059-1.146)\end{array}$ & $\begin{array}{l}0.002 \\
<0.001\end{array}$ \\
\hline $\begin{array}{l}\text { Fibrinogen level } \\
\qquad \begin{array}{l}\geq 3.64 \mathrm{~g} / \mathrm{L} \\
\quad<3.64 \mathrm{~g} / \mathrm{L}\end{array}\end{array}$ & $\begin{array}{l}\text { I } \\
0.64 I(0.525-0.782)\end{array}$ & $<0.001$ & $\begin{array}{l}\text { I } \\
0.777(0.630-0.958)\end{array}$ & 0.018 \\
\hline
\end{tabular}

(Continued) 
Table 2 (Continued).

\begin{tabular}{|l|l|l|l|l|}
\hline \multirow{2}{*}{ Variable } & \multicolumn{2}{|l|}{ Univariate } & \multicolumn{2}{l|}{ Multivariate } \\
\cline { 2 - 5 } & HR (95\% CI) & P & HR (95\% CI) & P \\
\hline $\begin{array}{l}\text { NLR } \\
\geq 2.23 \\
<2.23\end{array}$ & 1 & $<0.001$ & I & 0.060 \\
\hline $\begin{array}{l}\text { PLR } \\
\geq 169.2 \\
<169.2\end{array}$ & $0.602(0.496-0.730)$ & & $0.789(0.617-1.010)$ \\
\hline $\begin{array}{l}\text { PNI } \\
\geq 41.1 \\
<41.1\end{array}$ & 1 & $<0.001$ & & \\
\hline
\end{tabular}

Abbreviations: $\mathrm{Cl}$, confidence interval; HR, hazard ratio; eLNs, examined lymph nodes; PT, prothrombin time; APTT, activated partial thromboplastin time; NLR, neutrophil to lymphocyte ratio; PLR, platelet to lymphocyte ratio; PNI, prognostic nutritional index.

\section{Discussion}

We retrospectively analyzed a large sample of patients. The results provide strong evidence that an elevated preoperative fibrinogen is an independent prognostic parameter of worse OS and CSS in patients with nonmetastatic CRC. Importantly, we found a threshold level for use of fibrinogen as a prognostic factor, and 3.64 may be a suitable cut-off. In addition, we developed prediction models for patients based on demographic and clinicopathologic data. In contrast to TNM staging, nomograms estimate risk based on several variables and provide a more individualized prediction of outcome.

Previous studies indicated that fibrinogen was correlated with tumor stage in various types of cancer. ${ }^{21,26,27} \mathrm{In}$ our study, we analyzed additional clinicopathological factors in nonmetastatic CRC patients and found that preoperative fibrinogen levels also associated with tumor differentiation and tumor location. Interestingly, our results suggest that fibrinogen is not correlated with $\mathrm{pN}$ category. Elevated fibrinogen levels were not correlated with lymph node metastasis in our cohort, but this result does not agree with those of other studies. ${ }^{21,27}$ The reason for this may be the existence of individual differences. However, the underlying mechanisms remain unclear, and further studies are necessary to elucidate these mechanisms.

In clinical studies, preoperative fibrinogen was an independent marker of poor prognosis in various cancers. ${ }^{26-30}$ Son et al suggested that preoperative hyperfibrinogenemia was significantly correlated with poor survival in 624 patients with nonmetastatic colon cancer. ${ }^{20}$ Tang et al suggested that elevated preoperative fibrinogen levels were correlated with distant metastases and poor prognosis after curative resection in 341 patients with CRC. ${ }^{31}$ Sun et al reported similar results in 255 patients with CRC. ${ }^{32}$ However, a retrospective study involving 652 CRC patients demonstrated that preoperative fibrinogen levels were associated with tumor stage but did not predict the

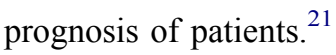

In our study, we first analyzed fibrinogen as a continuous variable. Although the univariate analysis indicated that the preoperative fibrinogen levels were associated with prognosis of OS and CSS, these findings were not confirmed in the multivariate analysis. One reason for this result may be that the effect of multicollinearity existed between fibrinogen and other independent prognostic factors, and that fibrinogen was not a very good prognostic factor as a continuous variable.

In contrast, using the restricted cubic spline, we observed that at the level of 3.6-3.7 $\mathrm{g} / \mathrm{L}$, the cohort was divided into two parts (Figure 1). We believe that there was a threshold level for use of fibrinogen as a prognostic factor, and subsequent tests supported this hypothesis (Supplementary Figure 1). Consequently, the optimal cutoff value was 3.64 using the BIC method and this cut-off converted fibrinogen to a dichotomous variable. ${ }^{23}$ The Kaplan-Meier estimates of the survival rate showed significantly different outcomes for the two proposed risk groups $(\mathrm{P}<0.001$, Figure 2$)$. Moreover, we found that preoperative fibrinogen as a dichotomous variable was an independent prognostic factor (Table 2 and Supplementary Table 3). And then, we have developed prognostic nomograms for OS and CSS based on the multivariable model 
A

Points

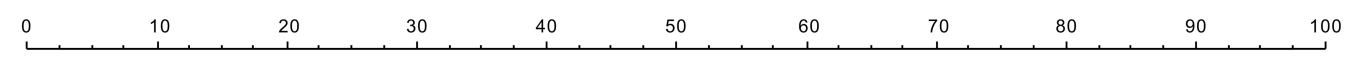

Age

pT stage

$\mathrm{pN}$ stage

Albumin level $(\mathrm{g} / \mathrm{L})$

The total number of eLNs

TDs

Fibrinogen level $(\mathrm{g} / \mathrm{L})$

Total Points

3-year survival

5-year survival

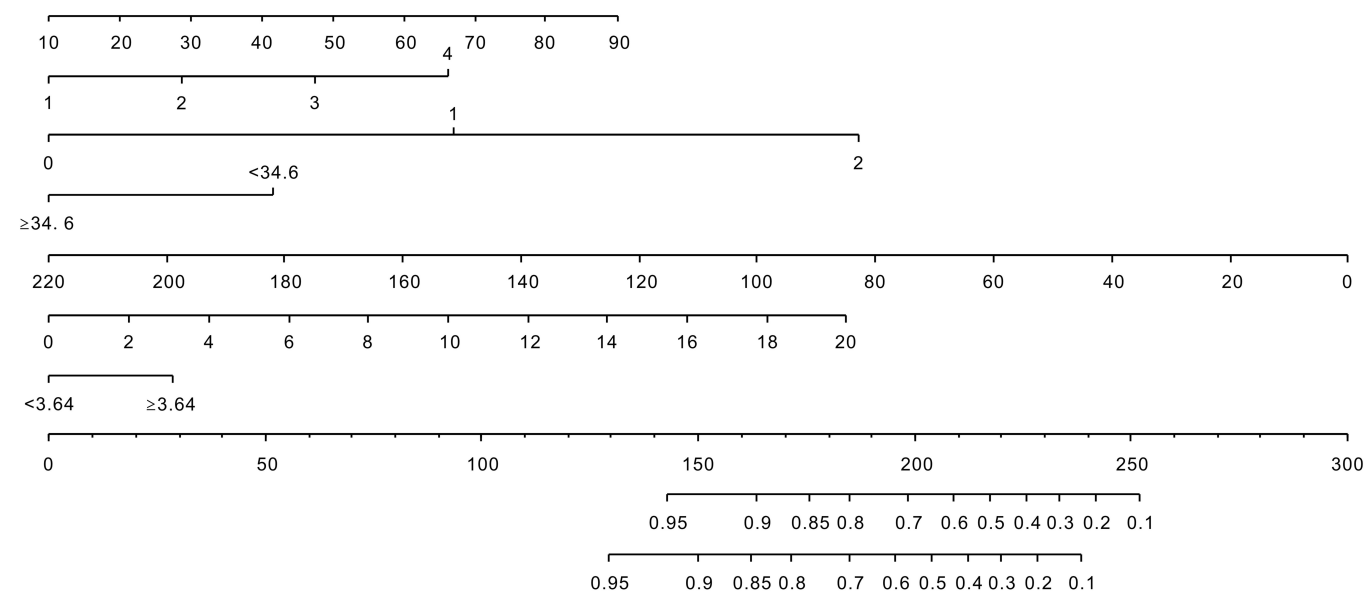

B

Points
$\mathrm{pT}$ stage
$\mathrm{pN}$ stage
Neutrophil count $\left(10^{9} / \mathrm{L}\right)$
Lymphocyte count $\left(10^{9} / \mathrm{L}\right)$
Albumin level $(\mathrm{g} / \mathrm{L})$
TDs
Fibrinogen level $(\mathrm{g} / \mathrm{L})$
Total Points
3-year survival
5-year survival

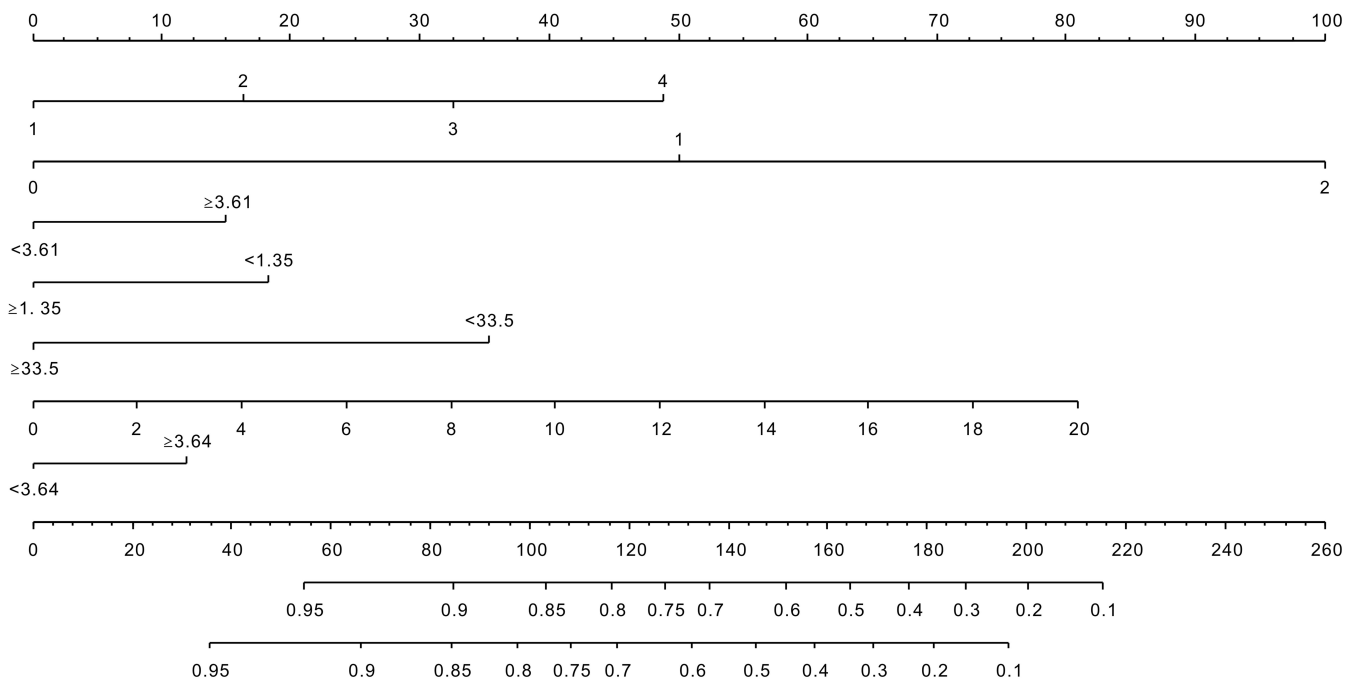

Figure 3 Nomograms developed for predicted overall survival $(\mathbf{A})$ and cancer-specific survival $(\mathbf{B})$ in patients with nonmetastatic CRC. Locate the patient's pT stage and draw a straight line toward the "Points" axis to determine the score associated with that PT stage. Repeat the process for each variable, sum the scores obtained for each covariate, and locate this sum on the "Total Points" axis. Draw a straight line straight downwards to determine the likelihood of 3- or 5-year OS and CSS.

Abbreviations: eLNs, examined lymph nodes; TDs, tumor deposits.

and the nomogram discrimination was superior to TNM classification. In summary, preoperative fibrinogen was a valuable factor in prognostic prediction.

Comparisons of both OS and CSS stratified by age were performed in our cohort (Supplementary Figure 2). It is of note that fibrinogen was significantly correlated with survival in younger patients but the association became less apparent in older patients. To the best of our knowledge, this study is the first to report such a phenomenon. The reasons for this are unclear. Based on this internal mechanism, we can carry out further analysis. New therapies may exist with potential implications for improving outcomes. In clinical practice, based on the nomogram, we would recommend that high-risk 
patients with relatively poor prognosis receive adjuvant therapy more actively.

Fibrinogen plays an indispensable role in cancer progression. ${ }^{33-36}$ Steinbrecher et al suggested that fibrinogen was associated with the development of inflammationdriven malignancy. ${ }^{33}$ In addition, studies have shown that fibrinogen can bind growth factors from the fibroblast growth factor (FGF), platelet-derived growth factor (PDGF), and transforming growth factor- $\beta$ (TGF- $\beta$ ) families. ${ }^{37,38}$ These growth factors may regulate cancer cell proliferation, invasion, and migration. ${ }^{39}$

Our study had a large sample compared to previous studies. However, the present study has several limitations. First, our study was retrospective and data were obtained from a single institution in China. Second, the prediction models obtained from our sample lacked external validation, and thus further studies with different populations are necessary to confirm our model.

\section{Conclusion}

In summary, preoperative fibrinogen level may be used as an independent prognostic parameter in patients with nonmetastatic CRC. The developed nomograms can help predict the individual risk of OS and CSS in patients operated for CRC.

\section{Abbreviations}

AJCC, American Joint Committee on Cancer; UICC, the Union for International Cancer Control; TNM, the tumornode-metastasis; CRC, colorectal cancer; NLR, neutrophil to lymphocyte ratio; PLR, platelet to lymphocyte ratio; PNI, prognostic nutritional index; eLNs, examined lymph nodes; TDs, tumor deposits; CI, confidence interval; HR, hazard ratio; OS, overall survival; CSS, cancer-specific survival.

\section{Data Sharing Statement}

The data supporting the founding of this paper are presented in this manuscript (i.e. Tables, Figure and Reference). Relevant data can be provided from the corresponding author on reasonable request.

\section{Ethics Approval and Consent to Participate}

This study was approved by the Research Ethics Committee of China Medical University. Written informed consent was obtained from all patients included consent to access their medical records. The study complies with the ethical principles described in the Declaration of Helsinki.

\section{Consent for Publication}

Written informed consent was obtained from the patient for publication of this report and any accompanying images.

\section{Acknowledgments}

We thank the Department of Surgical Oncology of First Hospital of China Medical University and the College of China Medical University for technical assistance.

\section{Funding}

This work was supported by the Overseas Training Project of Liaoning General Higher Education (2019GJWYB022), Major Scientific and Technological Special Project of Liaoning Province of China (2019JH1/10300007) and Natural Science Foundation of Liaoning Province of China (2019-MS-390).

\section{Disclosure}

The authors declare that they have no conflicts of interest.

\section{References}

1. Torre LA, Bray F, Siegel RL, et al. Global cancer statistics, 2012. CA Cancer J Clin. 2015;65(2):87-108. doi:10.3322/caac.21262

2. Martinez-Useros J, Garcia-Foncillas J. Obesity and colorectal cancer: molecular features of adipose tissue. $J$ Transl Med. 2016;14:21.

3. Le Marchand L, Wilkens LR, Kolonel LN, Hankin JH, Lyu LC. Associations of sedentary lifestyle, obesity, smoking, alcohol use, and diabetes with the risk of colorectal cancer. Cancer Res. 1997;57:4787-4794.

4. Russo A, Franceschi S, La Vecchia C, et al. Body size and colorectal-cancer risk. Int $J$ Cancer. 1998;78(2):161-165. doi:10.1002/(SICI)1097-0215(19981005)78:2<161::AID-IJC7>3.0. $\mathrm{CO} ; 2-\mathrm{X}$

5. Ashktorab H, Paydar M, Yazdi S, et al. BMI and the risk of colorectal adenoma in African-Americans. Obesity. 2014;22(5):1387-1391. doi:10.1002/oby.20702

6. Kitahara CM, Berndt SI, de González AB, et al. Prospective investigation of body mass index, colorectal adenoma, and colorectal cancer in the prostate, lung, colorectal, and ovarian cancer screening trial. J Clin Oncol. 2013;31(19):2450-2459. doi:10.1200/JCO.2012.48.4691

7. Matsuo K, Mizoue T, Tanaka K, et al. Development and evaluation of cancer prevention strategies in Japan. Association between body mass index and the colorectal cancer risk in Japan: pooled analysis of population-based cohort studies in Japan. Ann Oncol. 2012;23 (2):479-490. doi:10.1093/annonc/mdr143

8. Hari DM, Leung AM, Lee JH, et al. AJCC Cancer Staging Manual 7th edition criteria for colon cancer: do the complex modifications improve prognostic assessment? J Am Coll Surg. 2013;217 (2):181-190. doi:10.1016/j.jamcollsurg.2013.04.018

9. McMillan DC. The systemic inflammation-based glasgow prognostic score: a decade of experience in patients with cancer. Cancer Treat Rev. 2013;39(5):534-540. doi:10.1016/j.ctrv.2012.08.003

10. Canna K, McArdle PA, McMillan DC, et al. The relationship between tumour T-lymphocyte infiltration, the systemic inflammatory response and survival in patients undergoing curative resection for colorectal cancer. Br J Cancer. 2005;92(4):651-654. doi:10.1038/sj. bjc.6602419 
11. Park JH, Watt DG, Roxburgh CS, et al. Colorectal cancer, systemic inflammation, and outcome: staging the tumor and staging the host. Ann Surg. 2016;263(2):326-336. doi:10.1097/SLA.0000000000001122

12. Roxburgh CS, McMillan DC. The role of the in situ local inflammatory response in predicting recurrence and survival in patients with primary operable colorectal cancer. Cancer Treat Rev. 2012;38 (5):451-466. doi:10.1016/j.ctrv.2011.09.001

13. Richards $\mathrm{CH}$, Leitch EF, Horgan PG, et al. The relationship between patient physiology, the systemic inflammatory response and survival in patients undergoing curative resection of colorectal cancer. $\mathrm{Br}$ $J$ Cancer. 2010;103(9):1356-1361. doi:10.1038/sj.bjc.6605919

14. Tennent GA, Brennan SO, Stangou AJ, et al. Human plasma fibrinogen is synthesized in the liver. Blood. 2007;109(5):1971-1974. doi:10.1182/blood-2006-08-040956

15. Blombäck B, Hessel B, Hogg D, Therkildsen L. A two-step fibrinogen-fibrin transition in blood coagulation. Nature. 1978;275 (5680):501-505. doi:10.1038/275501a0

16. Martini WZ. Fibrinogen metabolic responses to trauma. Scand J Trauma Resusc Emerg Med. 2009;17(1):2. doi:10.1186/17577241-17-2

17. Redman CM, Xia H. Fibrinogen biosynthesis. Assembly, intracellular degradation, and association with lipid synthesis and secretion. Ann N Y Acad Sci. 2006;936(1):480-495. doi:10.1111/j.1749-6632.2001. tb03535.x

18. Erdogan S, Yilmaz FM, Yazici O, et al. Inflammation and chemerin in colorectal cancer. Tumour Biol. 2016;37(5):6337-6342. doi:10.10 07/s13277-015-4483-y

19. Allin KH, Bojesen SE, Nordestgaard BG. Inflammatory biomarkers and risk of cancer in 84,000 individuals from the general population. Int J Cancer. 2016;139(7):1493-1500. doi:10.1002/ijc.30194

20. Son HJ, Park JW, Chang HJ, et al. Preoperative plasma hyperfibrinogenemia is predictive of poor prognosis in patients with nonmetastatic colon cancer. Ann Surg Oncol. 2013;20(9):2908-2913. doi:10.1245/s10434-013-2968-8

21. Pedrazzani C, Mantovani G, Salvagno GL, et al. Elevated fibrinogen plasma level is not an independent predictor of poor prognosis in a large cohort of Western patients undergoing surgery for colorectal cancer. World J Gastroenterol. 2016;22(45):9994-10001. doi:10.37 48/wjg.v22.i45.9994

22. Onodera T, Goseki N, Kosaki G. [Prognostic nutritional index in gastrointestinal surgery of malnourished cancer patients]. Nihon Geka Gakkai Zassh. 1984;85:1001-1005. Japanese.

23. Volinsky CT, Raftery AE. Bayesian information criterion for censored survival models. Biometrics. 2000;56(1):256-262. doi:10.1111/ j.0006-341X.2000.00256.x

24. Harrell FE, Lee KL, Pollock BG. Regression models in clinical studies: determining relationships between predictors and response. J Natl Cancer Inst. 1988;80(15):1198-1202. doi:10.1093/jnci/80.15. 1198

25. Cleophas TJ. Clinical trials: spline modeling is wonderful for nonlinear effects. Am J Ther. 2016;23(3):e844-9. doi:10.1097/MJT.0b 013e318250f779

26. Polterauer S, Grimm C, Seebacher V, et al. Plasma fibrinogen levels and prognosis in patients with ovarian cancer: a multicenter study. Oncologist. 2009;14(10):979-985. doi:10.1634/theoncologist.20090079

Cancer Management and Research

\section{Publish your work in this journal}

Cancer Management and Research is an international, peer-reviewed open access journal focusing on cancer research and the optimal use of preventative and integrated treatment interventions to achieve improved outcomes, enhanced survival and quality of life for the cancer patient.
27. Yamashita H, Kitayama J, Kanno N, Yatomi Y, Nagawa H. Hyperfibrinogenemia is associated with lymphatic as well as hematogenous metastasis and worse clinical outcome in T2 gastric cancer. BMC Cancer. 2006;6(1):147. doi:10.1186/1471-2407-6-147

28. Sheng L, Luo M, Sun X, Lin N, Mao W, Su D. Serum fibrinogen is an independent prognostic factor in operable nonsmall cell lung cancer. Int J Cancer. 2013;133:2720-2725.

29. Tang LQ, Chen QY, Guo SS, et al. The impact of plasma Epstein-Barr virus DNA and fibrinogen on nasopharyngeal carcinoma prognosis: an observational study. Br J Cancer. 2014;111 (6):1102-1111. doi:10.1038/bjc.2014.393

30. Polterauer S, Seebacher V, Hefler-Frischmuth K, et al. Fibrinogen plasma levels are an independent prognostic parameter in patients with cervical cancer. Am J Obstet Gynecol. 2009;200(6):647.e1-7. doi:10.1016/j.ajog.2009.01.008

31. Tang L, Liu K, Wang J, Wang C, Zhao P, Liu J. High preoperative plasma fibrinogen levels are associated with distant metastases and impaired prognosis after curative resection in patients with colorectal cancer. J Surg Oncol. 2010;102(5):428-432. doi:10.1002/jso.21668

32. Sun ZQ, Han XN, Wang HJ, et al. Prognostic significance of preoperative fibrinogen in patients with colon cancer. World $J$ Gastroenterol. 2014;20(26):8583-8591. doi:10.3748/wjg.v20.i26. 8583

33. Steinbrecher KA, Horowitz NA, Blevins EA, et al. Colitis-associated cancer is dependent on the interplay between the hemostatic and inflammatory systems and supported by integrin $\alpha \mathrm{M} \beta 2$ engagement of fibrinogen. Cancer Res. 2010;70(7):2634-2643. doi:10.1158/00085472.CAN-09-3465

34. Shu YJ, Weng H, Bao RF, et al. Clinical and prognostic significance of preoperative plasma hyperfibrinogenemia in gallbladder cancer patients following surgical resection: a retrospective and in vitro study. BMC Cancer. 2014;14(1):566. doi:10.1186/1471-2407-14-566

35. Staton CA, Brown NJ, Lewis CE. The role of fibrinogen and related fragments in tumour angiogenesis and metastasis. Expert Opin Biol Ther. 2003;3(7):1105-1120. doi:10.1517/14712598.3.7.1105

36. Palumbo JS, Talmage KE, Massari JV, et al. Platelets and fibrin(ogen) increase metastatic potential by impeding natural killer cell-mediated elimination of tumor cells. Blood. 2005;105(1):178-185. doi:10.11 82/blood-2004-06-2272

37. Silvestris N, Scartozzi M, Graziano G, et al. Basal and bevacizumab-based therapy-induced changes of lactate dehydrogenases and fibrinogen levels and clinical outcome of previously untreated metastatic colorectal cancer patients: a multicentric retrospective analysis. Expert Opin Biol Ther. 2015;15(2):155-162. doi:10.1517/14712598.2015.986452

38. Martino MM, Briquez PS, Ranga A, Lutolf MP, Hubbell JA. Heparin-binding domain of fibrin(ogen) binds growth factors and promotes tissue repair when incorporated within a synthetic matrix. Proc Natl Acad Sci U S A. 2013;110(12):4563-4568. doi:10.1073/ pnas. 1221602110

39. Witsch E, Sela M, Yarden Y. Roles for growth factors in cancer progression. Physiology. 2010;25(2):85-101. doi:10.1152/physiol. 00045.2009
The manuscript management system is completely online and includes a very quick and fair peer-review system, which is all easy to use. Visit http://www.dovepress.com/testimonials.php to read real quotes from published authors. 